\title{
Prospects of Artificial Intelligence Use for Business Monitoring: Legal Aspects
}

By

Dr. Mironova Svenlana

PhD in Law, Associate Professor Volgograd Institute of Management, Branch of the Russian Presidential Academy of National Economy and Public Administration Volgograd, Russia Correspondence: smironova2017@gmail.com
Dr. Usanova Victoria

PhD in Law, Associate Professor Volgograd Institute of Management, Branch of the Russian Presidential Academy of National Economy and Public Administration

Volgograd, Russia

Correspondence:vau_77@mail.ru 


\section{Abstract}

The article explores the prospects for the use of artificial intelligence in the field of monitoring the implementation of entrepreneurial activity, analyzes the existing control mechanisms, as well as the modern implementation of control tools using artificial intelligence in the Russian practice, for example, in the tax sphere, in order to identify cases of tax evasion by entrepreneurs. It is concluded that artificial intelligence can be used by Russian regulatory authorities to identify facts of unregistered entrepreneurial activity, as well as concealment of income by entrepreneurs. It is also proposed to introduce artificial intelligence for use by entrepreneurs themselves in order to monitor legal requirements to prevent cases of violation and avoid liability. For example, artificial intelligence could help entrepreneurs in choosing a tax regime, as well as warning in situations where there are risks of losing a special tax regime.

Key words: Artificial Intelligence; Entrepreneurial Activity; SelfEmployed; The Control; Taxes; Special Tax Regimes; Responsibility; Machine Learning 


\section{Introduction}

The use of artificial intelligence and machine learning brings both pros and cons to development. Many applications, or "use cases", of AI and machine learning already exist. At the same time, there are a number of risks associated with the use of artificial intelligence, which must be taken into account when developing the legal framework for this institution.

As noted in report «Artificial intelligence and machine learning in financial services», the lack of interpretability or "auditability" of AI and machine learning methods could become a macro-level risk. Similarly, a widespread use of opaque models may result in unintended consequences. As with any new product or service, there are important issues around appropriate risk management and oversight. It will be important to assess uses of AI and machine learning in view of their risks, including adherence to relevant protocols on data privacy, conduct risks, and cybersecurity. Adequate testing and 'training' of tools with unbiased data and feedback mechanisms is important to ensure applications do what they are intended to do (report «Artificial intelligence and machine learning in financial services»).

This is also true when using artificial intelligence in exercising control over entrepreneurs, since the identification of 
violations on their part entails prosecution. Is it already possible to entrust artificial intelligence to detect business disruptions?

\section{Materials and methods.}

The systemic analysis is the main method, employed during this study. It allows to consider the main directions of the use of artificial intelligence in the implementation of state control over persons engaged in entrepreneurial activity, as well as possible ways of using artificial intelligence by entrepreneurs in order to more effectively carry out business and follow the law in order to minimize its violations and reduce cases of prosecution.

The data sample includes information, hosted on official websites of the state authorities that exercise control in the field of entrepreneurial activity.

Authors analyze the foreign and Russian scientific literature on the legal aspects of artificial intelligence, including in the area of control activities (including tax control); considering certain issues of legal regulation of state control over entrepreneurs, as well as questions about the delineation of entrepreneurial activity and related activities, for example, self-employed persons whose activities do not require state registration. 


\section{Results}

The study resulted in the following conclusions. Artificial intelligence can be used by Russian regulatory authorities to identify facts of unregistered entrepreneurial activity, as well as concealment of income by entrepreneurs. It is also proposed to introduce artificial intelligence for use by entrepreneurs themselves in order to monitor legal requirements to prevent cases of violation and avoid liability. For example, artificial intelligence could help entrepreneurs in choosing a tax regime, as well as warning in situations where there are risks of losing a special tax regime.

The implementation of the legal regulation of artificial intelligence and its introduction into the practice of control activities of public authorities should be based on the principles of security, transparency and technological sovereignty. Important conditions for the use of artificial intelligence in supervisory activities should be noted the question of trust in the conclusions made by artificial intelligence and the definition of legal criteria for its work, as well as the need to train employees of control bodies to work with artificial intelligence.

\section{Discussion}

Artificial intelligence and machine learning are currently used around the world, and therefore the necessary legal regulation of 
the use of artificial intelligence is required. Such questions become the subject of scrutiny both in foreign studies (Ashley, 2017, Barfield, Pagallo, 2018, Buiten, 2019, Yadong, 2020, Wischmeyer, Rademacher, 2020 and others) and in the studies of russian scientists (Channov, 2019, Ponkin, Redkina, 2018, Kharitonova, 2019 and others).

In Russia, the legal regulation of artificial intelligence is only beginning to take shape in the system.

By the Decree of the President of the Russian Federation of 10.10.2019 N 490 "On the Development of Artificial Intelligence in the Russian Federation" in order to ensure the accelerated development of artificial intelligence in the Russian Federation, to conduct scientific research in the field of artificial intelligence, to increase the availability of information and computing resources for users, to improve the personnel training system In this area, the National Strategy for the Development of Artificial Intelligence for the period until 2030 has been approved. Following the Decree, budgetary appropriations for the implementation of the Decree should be provided for when drafting federal budgets for the next financial year and planning period in 2020-2030.

In accordance with the National Strategy, artificial intelligence is understood as a set of technological solutions that 
allows you to simulate human cognitive functions (including selflearning and finding solutions without a predetermined algorithm) and to obtain results when performing specific tasks that are comparable, at least, with the results of human intellectual activity. The complex of technological solutions includes information and communication infrastructure, software (including that using machine learning methods), processes and services for data processing and search for solutions.

The basic principles for the development and use of artificial intelligence technologies, compliance with which is mandatory when implementing the Strategy, are:

a) protection of human rights and freedoms: ensuring the protection of human rights and freedoms guaranteed by Russian and international legislation, including the right to work, and providing citizens with the opportunity to acquire knowledge and acquire skills for successful adaptation to the conditions of the digital economy;

b) security: the inadmissibility of the use of artificial intelligence in order to intentionally cause harm to citizens and legal entities, as well as the prevention and minimization of the risks of negative consequences of the use of artificial intelligence technologies; 
c) transparency: the understandability of the work of artificial intelligence and the process of achieving results, nondiscriminatory access of users of products that are created using artificial intelligence technologies to information about the algorithms used by these products for the operation of artificial intelligence;

d) technological sovereignty: ensuring the necessary level of independence of the Russian Federation in the field of artificial intelligence, including through the predominant use of domestic artificial intelligence technologies and technological solutions developed on the basis of artificial intelligence;

e) the integrity of the innovation cycle: ensuring close interaction of research and development in the field of artificial intelligence with the real sector of the economy;

f) Reasonable thrift: implementing and adapting, as a matter of priority, existing measures aimed at implementing state policy in the scientific, technical and other fields;

g) support for competition: the development of market relations and the inadmissibility of actions aimed at restricting competition between Russian organizations operating in the field of artificial intelligence. 
As noted in report "Artificial intelligence and machine learning in financial services», both public and private sector institutions may use Artificial intelligence technologies for regulatory compliance, surveillance, data quality assessment, and fraud detection.

AI and machine learning techniques are being used by regulated institutions for regulatory compliance, and by authorities for supervision. RegTech is often regarded as the subset of FinTech that focus on facilitating regulatory compliance more efficiently and effectively than existing capabilities.57 The total RegTech market is expected to reach $\$ 6.45$ billion by 2020 , growing at a compound annual growth rate (CAGR) of $76 \%$ (report «Artificial intelligence and machine learning in financial services»).

SupTech is the use of these technologies by public sector regulators and supervisors. Within SupTech, the objective of AI and machine learning applications is to enhance efficiency and effectiveness of supervision and surveillance.

In Russian literature, several problematic questions are raised regarding the use of artificial intelligence and self-learning software in relation to state financial control in the field of AML / CFT:

First, how much can you trust the conclusions and recommendations that artificial intelligence will convey? 
Secondly, how can the effectiveness of artificial intelligence be checked and what legal criteria should be used for such an assessment?

Thirdly, how much artificial intelligence should be integrated into the procedures of an agent of financial monitoring? Should artificial intelligence replace it in whole or in part? What requirements for artificial intelligence systems should a state financial control body make?

Fourth, it is very important to determine the distinction between the areas of responsibility of artificial intelligence and the employee, body or agent of financial monitoring (Tsindeliani, 2019).

Such questions arise not by chance, since the National Strategy indicates compliance with the principle of development and use of artificial intelligence technologies as transparency.

Government bodies in other countries pose the same issues. For example, the head of the Financial Crimes Department at FCA, talking about using artificial intelligence to keep criminal funds out of the financial system, notes the following: «How should machine learning sit alongside human decision-making? We see it as complementing, not replacing, human judgement. A feedback process is crucial to improving overall performance over time, with, 
for example, knowledge of which predictions were false positives (or false negatives) being used to continuously refine the model. The machines can direct the humans to the cases of most interest. But the software will deal in probabilities, not absolutes, and a person will need to make the final decision about whether intelligence is passed to the authorities. People also need to be testing the machine and governing it.» (Gruppetta, 2017).

Such issues are important in the activities of any control bodies, not only in the area of counteracting the legalization of proceeds from crime, but also in other areas related to entrepreneurial activity, starting from its registration. In the same time the idea of liability in the specific context of artificial intelligence systems is one such challenge that should be thoroughly explored (Hallevy, 2015).

Public authorities exercising control, including entrepreneurs should identify the main areas of digitization activities and the use of information technology in the field of monitoring and control.

For example, the Accounts Chamber of the Russian Federation, which has the right to exercise control over organizations that receive funds from the federal budget, pays great attention to the creation of digital infrastructure. The Development Strategy of the Accounts Chamber of the Russian Federation for 
2018-2024 determines priority development directions for the implementation of new tasks, taking into account the digitalization of information support for the activities of the Accounts Chamber on the implementation of external state audit (control) at a new qualitative level, where the task of creating a digital infrastructure to support the audit and analytical activity (Digital platform...).

Based on the Strategy, the Digital Transformation Department of the Accounts Chamber developed and approved the Digitalization Concept of the Accounts Chamber of the Russian Federation, which determines the format for building the Digital Platform and the workplace of the "Digital Inspector". With their help, it will be possible to expand the list of data sources used for auditing and improve their quality, apply modern methods of information management, reduce the complexity of traditional types of audits and ensure the development of strategic audit by creating risk-based and analytical models and using modern methods of predictive analytics.

As part of the implementation of the Digitalization Concept, a Digital Platform is being created in the Accounts Chamber, a software and hardware complex that provides data analysts with the necessary data and can use it to process them using the Digital 
Platform toolkit, receiving risk-oriented models, analytical models, and visual tools etc.

At the same time, there are a number of difficulties in implementing the concept, which are expressed in the following:

1. An indefinite number of heterogeneous data sources.

2. Weak and not always obvious relationships between data sources.

3. The problem with the quality of the data.

4. Difficulties with the choice of software. Due to licensing risks, the use of foreign software is not desirable, and Open Source software does not always fully meet the requirements.

5. Difficulties in finding employees with the necessary knowledge.

6. Long term approval and the process of public procurement of equipment.

7. Unavailability of the majority of employees to work in a new, digital format (Digital platform...).

Difficulties with the choice of software determines the implementation of such a principle of development and use of artificial intelligence technologies, indicated in the National Strategy, such as technological sovereignty. 
As can be seen from the list, a number of difficulties arise due to insufficient qualifications in the field of digital technologies, including the use of artificial intelligence, both of existing employees and in the selection of personnel. This applies to legal and economic specialists who directly exercise control, as well as technical specialists who implement information technologies in the work of state authorities.

In this regard, it becomes obvious the need to review the training of future lawyers, as well as students of other specialties, who in the future will both exercise control from the state bodies over entrepreneurs and engage in legal practice in organizations. $\mathrm{K}$. Ashley notes that it is also unclear what law students need to learn about technology. Law firms have long called for law schools to graduate "practice-ready" students but even firms seem confused about the kinds of technology the firms will require, whether to develop the technology in house or rely on external suppliers, and the skills and knowledge that would best prepare law students for evaluating and using the new technologies (Ashley, 2017).

The main task of the modern university, which prepares future lawyers, is the combination of humanitarian and technical knowledge and skills, as well as the development of students' skills in working with modern technical means (Mironova, Bogdanova, Simonova,2019). 
AI regulation is not a specialized sub-discipline, but affects the entire legal system and thus concerns all lawyers. Machine learning-based technology, which lies at the heart of what is commonly referred to as AI, is increasingly being employed to make policy and business decisions with broad social impacts, and therefore runs the risk of causing wide-scale damage. At the same time, AI technology is becoming more and more complex and difficult to understand, making it harder to determine whether or not it is being used in accordance with the law (Wischmeyer, Rademacher, 2020).

Thus, it is necessary for a lawyer to study the basics of the legal regulation of artificial intelligence and to understand situations when artificial intelligence is used, to assess the legal consequences of such use, including when artificial intelligence is used to supervise the activities of entrepreneurs.

In Russia, tax authorities (the Federal Tax Service of the Russian Federation) have the most experience in the use of artificial intelligence, which successfully apply information technologies both in tax administration and tax control (Migacheva, 2018, Rodygina, 2018, Shabanova, 2020), including the use of special programs, such as ASK VAT-2 (Timoshenko, 2017). 
In 2017, the Federal Tax Service of Russia began to use artificial intelligence in the Personal Account for individuals. A robot chat works, which helps people solve certain issues related to tax administration. The FTS database contains 150 thousand different life situations that robot chat must learn.

Modern technologies have great potential for a qualitative change in tax administration in a digitalized economy. The Federal Tax Service of Russia, heading the international project "Forum on Tax Administration of the OECD", one of the most authoritative and representative international cooperation platforms for tax administrations of the world in the field of electronic services and digital delivery channels, is studying information technologies that may be useful for tax administrations. The best of the world experience - mobile technologies, artificial intelligence, smart portals and big data technologies - is used in their practice and creates a global control and analytical system (Tsindeliani, 2019).

The implementation of tax control using artificial intelligence is possible for various tasks: to identify entrepreneurial activity without state registration (for example, leasing commercial real estate); to identify income from which taxes have not been paid; to identify cases of concealment of income and objects of taxation. This is especially true at the present time in connection with the 
experiment to introduce a tax regime in Russia for the selfemployed (Mironova, Stetsenko, 2019).

Artificial intelligence and data analysis will facilitate decision-making on taxpayer audits - for example, if the risks of taxpayer non-payment of taxes are identified based on data received by the tax authority from various sources, a decision may be made on an unscheduled audit.

The use of artificial intelligence can also help in the fight against tax evasion at the international level. As noted in the literature, the use of an artificial intelligence tax treaty assistant with regard to resolving issues and problems in respect of the principal purpose test as proposed in relation to the $\mathrm{OECD} / \mathrm{G} 20$ Base Erosion and Profit Shifting initiative. As the PPT is very complex and ambiguous, what AI learns in dealing with those cases could be put to use regarding other rules of a similar degree of complexity and ambiguity and with a largely similar purpose and nature. AI could eventually be applied to all types of anti-tax avoidance legislation. By augmenting the power of AI, a very effective means of preventing tax avoidance on a global scale should be possible (Kuzniacki, 2018). It should be agreed with the author that the application of $\mathrm{AI}$ in the domain of international tax avoidance is likely to be a "game changer" by not only improving 
the work of tax advisers and tax administrations across the world, but also the performance of tax systems globally.

Entrepreneurs can use artificial intelligence to prevent violations of the law, for example, on the basis of machine learning, to assess the risks of possible inspections by the tax authorities, determine the possibility of transition to another tax regime, etc.

Thus, the use of artificial intelligence can be beneficial to both entrepreneurs and regulatory authorities. In this case, the basic principles of the development and use of artificial intelligence technologies must be observed.

\section{References}

1. Artificial intelligence and machine learning in financial services. Market developments and financial stability implications. https://www.fsb.org/publications/ (accessed 20 March 2020).

2. Ashley K. (2017) Introducing AI \& Law and Its Role in Future Legal Practice. Artificial Intelligence and Legal Analytics: 3-37.

3. Barfield W. (Ed), Pagallo U. (Ed) (2018) Research Handbook on the Law of Artificial Intelligence. UK Edward Elgar Publishing: 702. 
4. Buiten M. (2019) Towards Intelligent Regulation of Artificial Intelligence. European Journal of Risk Regulation 10(1): 41-59.

5. Channov S. (2019) The use of blockchain technologies for maintaining registers in the field of public administration. Administrative law and process 12: 29 - 34 .

6. Digital platform of the Accounts Chamber of the Russian Federation. https://globalcio.ru/live/projects/3135/ (accessed 20 March 2020).

7. Gruppetta R. (2017) Using artificial intelligence to keep criminal funds out of the financial system. https://www.fca.org.uk/news/speeches/using-artificialintelligence-keep-criminal-funds-out-financial-system (accessed 19 March 2020).

8. Gubin E. (Ed) (2019) Entrepreneurial law of Russia: results, trends and development paths: monograph. Moscow: Justicinform: 664 .

9. Hallevy G. (2015) Liability for Crimes Involving Artificial Intelligence Systems. Springer International Publishing Switzerland: 257. 
10. Kharitonova Yu. (2019) The legal regime of the results of artificial intelligence. Modern information technology and law: monograph: $68-83$.

11. Kuzniacki B (2018) The Artificial Intelligence Tax Treaty Assistant: Decoding the Principal Purpose Test (August 20, 2018).

12. Migacheva E. (2018) Tax control in the development of the digital economy. Financial law 8: 21 - 25.

13. Mironova S. (2019) The use of digital technologies in the financial activities of municipalities: the experience of Russia and European countries. Financial Law Review 14(2): 59-75.

14. Mironova S., Bogdanova T., Simonova S. (2019) The introduction of digital technologies in the educational process of training lawyers SHS Web of Conferences 69, 00079 (2019). $\quad$ https://www.shsconferences.org/articles/shsconf/pdf/2019/10/shsconf_cildia $\underline{\text { h2019 00079.pdf. }}$

15. Mironova S., Stetsenko E. (2019) Taxation of self-employed persons (some issues of applying professional income tax). Law and Economics 9: 64 - 73. 
16. Ponkin I., Redkina A. (2018) Artificial intelligence from the point of view of law. Bulletin of RUDN University. Series: Jurisprudence 1 .

17. Rodygina V. (2018) Digitalization of VAT tax control: legal consequences and prospects. Financial Law 9: 31 - 34.

18. Shabanova I. (2020) The use of information technology during tax control upon termination of the legal entity. Financial Law 1: 30 - 33.

19. Timoshenko V. (2017) Improving control over the calculation and payment of VAT on the basis of "ASK VAT-2". Law and Economics 11: 61 - 65.

20. Tsindeliani I. (2019) Financial Law in a Digital Economy: Monograph. Moscow, Prospect: 320.

21. Wischmeyer, T. (Ed), Rademacher, T. (Ed) (2020) Regulating Artificial Intelligence. Springer Nature Switzerland AG: 388.

22. Yadong C. (2020) Artificial Intelligence and Judicial Modernization. Springer Singapore: 224. 